\title{
PATROCÍNIO EMPRESARIAL E INCENTIVOS FISCAIS A CULTURA NO BRASIL: ANÁLISE DE UMA EXPERIÊNCIA RECENTE
}

\author{
José Carlos Garcia Durand \\ Coordenador do CECC (Centro de Estudos da Cultura e do \\ Consumo) da EAESP/FGV. \\ Maria Alice Gouveia \\ Técnica da Secretaria Municipal de Cultura de São Paulo. \\ Atriz, Produtora Cultural e Membro do Conselho Municipal de \\ Cultura da Cidade de São Paulo.
}

RESUMO: O artigo examina o estado geral da implantação no Brasil, nos anos 90 , da legislação federal, municipal e estadual de incentivo fiscal à cultura. Mostra as características mais comuns - os pontos fortes e as deficiências $-e$, quando disponíveis, resultados numéricos extensivos até 1995. A análise apóia-se em um levantamento junto às autoridades culturais responsáveis, sendo que as leis ou projetos de lei foram comparados em suas virtudes de agilidade de operação para o poder público e a comunidade cultural, atrativo para empresários, prevenção de fraudes etc.

ABSTRACT: The article examines the implantation of fiscal incentives for culture in Brazil from 1986 to 1995, in the federal, state and municipal levels. The analysis is based on cultural authorities survey and shows the main challenges to the cultural policy modernization in Brazil. It also considers the main features of the incentive laws as ways to avoid fiscal frauds, describes advantages of these laws to the government, community and companies. Besides that, the article provides some quantitative information and analyses the results obtained until 1995.

PALAVRAS-CHAVE: patrocínio empresarial, incentivos fiscais, cultura, Brasil.

KEY WORDS: business sponsorship, fiscal incentives, culture, Brazil. 
Se por mecenato entendermos os patrocínios e doações econômicas de vulto, por meio dos quais pessoas de fortuna, por livre e espontânea vontade, enriquecem o patrimônio e o repertório cultural coletivos, será forçoso reconhecer que se trata de fato incomum no Brasil.'

Basta lembrar, de início, que o Brasil não conheceu um patronato mecenas antes de se iniciar a implantação no país do moderno sistema de patrocínio corporativo às artes, ${ }^{2} \mathrm{e}$ salientar que essa ausência, por sua vez, contribuiu para que este sistema surgisse com certo atraso e se desenvolvesse com dificuldade, quando se compara o Brasil com outros países.

O moderno patrocínio corporativo tem como uma primeira característica o fato de que é a empresa - e não o empresário ou sua família - o agente da ação. Ou seja, ainda que possa haver a mão forte de um proprietário ou presidente sensível às artes, as doações ou patrocínios são decididos em função de uma estratégia corporativa e não de caráter individual-familiar. Argumenta-se que no Brasil esse grau de institucionalização ainda é muito frágil e que a mudança de nomes na composição das diretorias das empresas afeta enormemente a continuidade de sua ação cultural.

Outra característica é que, no Brasil, doações ou patrocínios costumam resultar de decisões tomadas com o objetivo de um retorno de prestígio para a imagem da empresa e/ou de seus produtos. Ou, para usar o jargão do próprio marketing cultural, o investimento em cultura serve para "qualificar" o conjunto das ações de comunicação da empresa com o mercado e com a sociedade. Não se confunde assim com os aportes financeiros feitos em produtos da indústria cultural, âmbito no qual a cultura se exprime sob a forma de mercadorias destinadas a gerar lucro econômico para seus produtores.

Para a busca de doações e patrocínios, costumam ser necessários profissionais especializados em dar a iniciativas culturais o formato de projetos de interesse empresarial. Esse trabalho inclui, entre outros aspectos, a habilidade e a sensibilidade em localizar pontos de afinidade entre o evento ou o bem cultural para o qual se procura recursos e a posição que determinada empresa ocupa ou pretende ocupar no mercado, em termos de tamanho, ramo de atividade, perfil de público consumidor etc.

Além de profissionais especializados fazendo a mediação entre o campo empresarial e o cultural, esse sistema com freqüência também supõe certos benefícios assegurados por lei a doadores ou patrocinadores. Em geral, são leis que estabelecem benefícios tributários (nos impostos sobre a renda, sobre a transmissão do patrimônio ou outros) para pessoas físicas ou jurídicas que fizerem doações ou patrocínios culturais ou ainda que decidirem investir em cultura com finalidade de lucro. Finalmente, como resultado de uma prática que se rotiniza e que tende a atrair um número crescente de empresas, esse siste-

Para a busca de doaçóes
e patrocínios, costumam
ser necessários
profissionais
especializados em dar às
iniciativas culturais o
formato de projetos de
interesse empresarial.
ma costuma favore-

cer o surgimento de associações para orientar os empresários em suas decisões em matéria de doações e patrocínios. ${ }^{3}$ Ao enaltecer as virtudes do patrocínio cultural, ao estimular o debate do assunto e ao divulgar estatísticas a respeito, tais associações ajudam a aumentar o número de empresas que patrocinam a cultura. Contribuem para que se conheçam os totais aplicados pelas empresas conforme seu tamanho e ramo de negócios, assim como o tipo de atividade cultural fomentada. Igualmente, ajudam a identificar quais são as áreas que se apresentam aos homens de empresa como concorrentes à área de cultura na disputa pela verba institucional de reforço de imagem. A propósito, cabe esclarecer que as principais dentre essas áreas são: esporte, meio ambiente, assistência social e educação, ciência e tecnologia. Em um país como o Brasil, no qual a devastação ecológica e os níveis de pobreza são mundialmente criticados, e no qual o esporte faz vibrar multidões, é fácil concluir que a opção "cultura" enfrenta fortes adversários, nas decisões das empresas.

$\mathrm{O}$ moderno mecenato corporativo surgiu nos Estados Unidos, nos anos $60,{ }^{4} \mathrm{em}$ uma época de prosperidade econômica e de início de uma mudança muito significativa nas estratégias empresariais. Trata-se da passagem da produção de massa e da comunicação indiscriminada com o mercado, através da mídia broadcasting, para uma etapa na qual os produtos são feitos para fatias cada vez mais pequenas do mercado e divulgados por uma
1. Esta definiçāo exclui da categoria de mecenas as pessoas que fomentaram a cultura usando recursos públicos ou de terceiros, embora possam ter tido atuação chave no campo cultural, e também aqueles empresários que retiram prestigio do fato de constituírem conselhos de entidades culturais, sem a contrapartida de doações significativas. Numerosas pessoas celebradas como mecenas no Brasil, do século passado até hoje, não mereceriam ser assim chamadas, no rigor técnico da definição.

2. Ver, de J. C. Durand, "Business and culture in Brazil", a ser publicado em 1996 por Praeger Eds., Westpont/Londres, em antologia organizada por Rosanne Martorella sob o título Art and business: an international perspective on sponsorship (Versão original em português "Empresas e cultura no Brasil", caderno n. 8 da Série Didática Administração da Cultura, do Centro de Estudos da Cultura e do Consumo. São Paulo, maio 1995)

3. Entidades para coordenação e fomento da ação empresarial no campo da cultura existem hoje em catorze países. São eles: Alemanha, Áustria, Bélgica, Canadá, EUA, França, Grécia, Holanda, Hong-Kong, Inglaterra, Irlanda, Israel, Japão e Suécia. Essa relação foi apresentada pelo produtor cultural Yacoff Sarkovas, em "Arteempresa: parceria multiplicadora". In: MENDONÇA, M. (org.). Lei de incentivo à cultura: uma saida para a arte. São Paulo: Carthago \& Forte, 1994. p. 50.

4. Mais especificamente em 1967, quando liderados por Nelson Rockefeller, os empresários americanos criaram o Business Committee for the Arts. Este ajudou a canalizar 22 milhões de dólares para a cultura no ano em que foi criado, soma que atualmente ultrapassa um bilhāo de dólares anual, conforme anota Sarkovas no artigo citado. 
5. 0 elemento certamente mais embrionário ainda é a associação patrona para fomento à cultura. Embora não exista nenhuma instituição assim especializad no Brasil, é indispensável mencionar a existência, desde 1992, do GIFE - Grupo de Institutos. Fundações e Empresas. Fundados na premissa da cidadania participativa, os empresários ligados ao GIFE pretendem, através dele, "incentivar ações de parceria, 0 intercâmbio de idéias e a participação solidária na busca de alternativas para os problemas sociais brasileiros através da filantropia privada". Esse grupo atesta reunir cinqüent instituições, que movimentam cem milhões de dólares por ano de recursos próprios em projetos "de natureza social, econômica, cultural e científica".

6. Embora se trate de um mandato presidencial atípico, posto que terminado pelo vice-presidente em virtude do impeachment do presidente eleito, governo Fernando Collor/ltamar Franco (março de 1990 - dezembro de 1994) teve nada menos que cinco ministros da cultura, cada um com um perfil diverso.

7. Ver, a esse respeito, de J. C. Durand, os artigos: "A delicada fronteira entre empresa e cultura" , in: MENDONCA, Marcos (org.). Op.cit.; e "Profissionalizar a administração da cultura" , in: $R A E$ Revista de Administração de Empresas. Sāo Paulo, v. 36, n. 2, pp. 6-11, 1996. comunicação mais seletiva e dirigida. Dizem os teóricos da administração que isso corresponde ao movimento de amplitude mundial e irreversível de segmentação interna dos mercados nacionais de consumo.

É possível dizer que no Brasil dos anos 90 estão presentes todas as características até aqui mencionadas. Algumas, é claro, apenas de forma embrionária. ${ }^{5}$ Isso autoriza dizer que o moderno sistema de patrocínio corporativo à cultura está em fase de implantação e leva a admitir que se progresso maior ainda não houve é porque fatores adversos de maior amplitude ainda impõem efeitos paralisantes.

Entre estes há os de caráter macroeconômico: recessão prolongada e hiperinflação (de 1980 a 1994), queda nos lucros, elevadas margens de evasão e sonegação fiscal e constantes mudanças nas regras tributárias. Há também os de natureza político-administrativa: por exemplo, mudanças excessivas de comando da área cultural pública, além de desprofissionalização e baixos salários dos técnicos do setor. ${ }^{6}$ Ou ainda uma opinião pública não suficientemente exigente com relação ao comportamento ético, cívico e ambiental de suas empresas (embora inegáveis progressos estejam ocorrendo nesta frente, como se viu quando do preparo da Constituição em 1988 e do exercício de lobby político que desde então ela vem suscitando nas empresas privadas). A propósito, sabe-se que há ramos de negócios para os quais é mais aguda a necessidade de reparar imagem ou de reforçá-la positivamente através do marketing cultural: é o caso das indústrias de bebidas alcoólicas, de tabaco e da petroquímica, pela ameaça que oferecem à saúde humana e ao meio ambiente; ou o caso dos bancos, que trabalham uma mercadoria comum (dinheiro) e só podem se demarcar na mente do público em termos da associação de seu nome e logotipo com cultura, esporte ou beneficência. Finalmente, os de ordem cultural, entre os quais está o nível menos sofisticado de consumo cultural dos dirigentes de empresa brasileiros, quando comparado ao de seus colegas de países avançados. Também aqui, a elevação rápida dos níveis de escolaridade superior nesse segmento social, no Brasil, obriga a reconhecer que as coisas estão rapidamente melhorando.

Como os argumentos até aqui apresentados estão mais desenvolvidos em outras publicações, ${ }^{7}$ é mais interessante passar ao exame de um ponto específico bastante atual e em rela- ção ao qual há resultados de pesquisa ainda inéditos. Este ponto diz respeito à legislação fiscal até agora criada pelo poder público (federal, estadual e municipal) para incentivar empresários a fomentar cultura.

\section{A EXPERIÊNCIA DE INCENTIVOS FISCAIS À CULTURA NO BRASIL: 1986-95}

\section{A legislação federal: leis "Sarney"e "Rouanet"}

A primeira lei de incentivos fiscais à cultura foi de nível federal. Foi apresentada ao Congresso Nacional em 1972, mas só conseguiu aprovação definitiva em 1986, quando o parlamentar autor do projeto - José Sarney tornou-se Presidente da República pelo voto indireto e pelos azares de uma sucessão imprevista. Depois de duas décadas de regime militar, Sarney, eleito vice-presidente, tornou-se o primeiro presidente civil, assumindo o poder em virtude da morte de Tancredo Neves, o presidente escolhido pelo Congresso Nacional.

Conhecida como "lei Sarney", a primeira lei de incentivo teve vida relativamente curta. Ficou em vigor até março de 1990 e seus resultados quantitativos ainda não foram divulgados oficialmente nem avaliados com rigor. Sabe-se que o total de captação, durante toda sua vigência, foi da ordem de 450 milhões de dólares, mas não se conhece a distribuição desses recursos segundo sua origem ou destino. A particularidade mais criticada dessa lei foi a de que, ao não exigir aprovação técnica prévia de projetos culturais mas apenas o cadastramento como "entidade cultural", junto ao Ministério da Cultura, das pessoas e firmas interessadas em captar recursos das empresas, a lei teria favorecido muito abuso; como, entre outras razões, pelo fato de que qualquer nota fiscal emitida por uma entidade cadastrada poderia ser usada por seu destinatário para abatimento fiscal, independentemente de se referir ou não a despesa efetiva com projeto cultural. O número de cadastrados no Ministério da Cultura foi de 7.200, o que deve ter significado cerca de dez mil pessoas físicas ligadas à produção de cultura, em todo o país.

Outra crítica insistente era de que a lei não distinguia, entre as iniciativas culturais, aquelas que de fato precisavam de incentivo, podendo assim ser usada inclusive para grandes espetáculos de caráter nitidamente comercial. 
Finalmente, recriminava-se o fato de que a lei acolhia inclusive projetos culturais sem caráter público, como era o caso das edições de luxo de livros de arte, que as empresas gostam de oferecer como presente de fim de ano a seus fornecedores e clientes.

A Lei Sarney foi revogada junto com todas as demais leis de incentivo fiscal vigentes, por ocasião do primeiro plano de contenção inflacionária adotado pelo presidente Collor, em março de 1990. Em uma postura neoliberal extremada, Collor acreditou que o mercado substituiria o governo no fomento à cultura no país. Assim, determinou, logo após sua posse, o encerramento de atividades das principais instituições federais da área cultural. Após um período particularmente turbulento, em meados de 1991 foi aprovada uma nova lei de incentivo fiscal à cultura. É a lei $\mathrm{n}^{\circ}$ 8.313/91, elaborada quando era Ministro da Cultura o embaixador Sérgio Paulo Rouanet.

Essa nova lei introduziu a aprovação prévia de projetos por parte de uma comissão com representantes do governo e de entidades culturais. Criou três mecanismos de apoio: o FNC (Fundo Nacional de Cultura), que destina recursos diretamente a projetos culturais através de empréstimos reembolsáveis ou cessão a fundo perdido a pessoas físicas, a pessoas jurídicas sem fins lucrativos e a órgãos culturais públicos; os FICARTs (Fundos de Investimento Cultural e Artístico), que são disciplinados pela CVM (Comissão de Valores Mobiliários) e organizam formas de investimento em projetos; e finalmente o Incentivo a Projetos Culturais, que cria benefícios fiscais para os contribuintes do Imposto sobre a Renda que apoiarem projetos culturais sob forma de doação ou patrocínio.

Todavia, ao impedir a remuneração de intermediários, ao enrijecer o processo de avaliação de projetos e ao estabelecer em nível muito baixo o percentual de imposto que as empresas poderiam dirigir à cultura, a nova lei não conseguiu mobilizar parcela significativa dos recursos postos à disposição. ${ }^{8}$ Em 1994 , os 60 projetos viabilizados pela Lei Rouanet corresponderam a apenas $17,8 \%$ dos projetos aprovados. Foram 13,6 milhões de dólares usados pelos produtores culturais, ou seja, uma pequena parte do total de 100,8 milhões de dólares aprovado para o mesmo período. Como os resultados dos anos anteriores não foram muito diferentes, é lícito concluir que até fins de 1994 a Lei Rouanet tenha efetivamente canalizado à cultura uma quantia de recursos muito inferior à Lei Sarney.

No início da gestão de Francisco Weffort no Ministério da Cultura, em janeiro de 1995 , encarou-se a reforma da Lei Rouanet como tarefa prioritária. O percentual de imposto sobre a renda passível de ser usado como incentivo fiscal aumentou de 2 para $5 \%$. Além disso, os demais tipos de pessoa jurídica tornaram-se aptos a abater de seu imposto de renda recursos transferidos para projetos culturais, visto que anteriormente só as pessoas jurídicas tributadas com base no lucro real poderiam fazê-lo.

Desde que explicitadas na planilha de custos e sujeitas a exame técnico, passou a ser permitida a inclusão de despesas referentes à contratação de serviços para elabora-

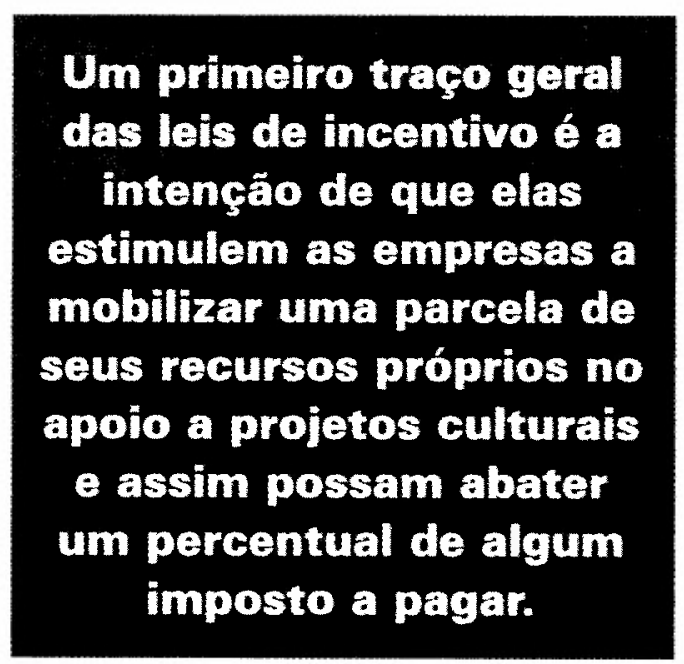
ção, difusão e divulgação de projetos culturais e para captação de recursos junto a contribuintes e incentivadores. Anteriormente, apenas os serviços de elaboração de projetos estavam previstos e ainda assim limitados a $10 \%$ do valor do projeto. Conseqüências positivas dessas medidas já estão sendo sentidas. Segundo José Álvaro Moisés, Secretário de Apoio Cultural do Ministério da Cultura, ${ }^{9}$ a média de 300 projetos anuais recebidos pela Comissão Nacional de Incentivo à Cultura (CNIC), no período 1993 - 94, já foi ultrapassada no primeiro semestre de 1995, durante o qual a Comissão recebeu 650 projetos. Se prosseguir nesse ritmo, o movimento de 1995 deverá ser o quádruplo dos anos anteriores. Para o fomento ao cinema, regulado por uma lei especial, a Lei do Audiovisual, os oito milhões de reais canalizados em 1994 deverão passar a 34 milhões até o fim de 1995. Assim, espera-se que o número de filmes de longa metragem resultantes salte de nove para 39 no mesmo período. $^{10}$

A partir das mudanças feitas em 1995, o Ministério da Cultura poderá delegar a análise, a aprovação e o acompanhamento de
8. Entenda-se aqui por recursos "postos à disposiçāo" o total dos impostos que o governo concorda, em determinado ano, em deixar de receber dos contribuintes para apoiar a cultura. Não significa uma massa de recursos nos cofres do governo e pronta para ser transferida aos artistas e produtores culturais. É apenas um limite superior de gastos que a autoridade financeira autoriza a autoridade cultural a aprovar, como somatório global dos orçamentos dos projetos aprovados.

9. Informação transmitida na abertura do evento "Economia da Cultura: as leis de incentivo". São Paulo, 12.09.95.

10. Dados fornecidos por representantes da Comissão de Valores Mobiliários (CVM), em evento recente. Dos 48 roteiros de filmes à busca de financiamento, oito já estão com os recursos captados junto a investidores no mercado. 
projetos a Estados e Municípios que tenham suas próprias leis de incentivo à cultura e que estruturem um órgão colegiado de avaliação de projetos composto por representantes dos diversos segmentos culturais e artísticos em proporção no mínimo paritária em relação aos representantes do governo.

\section{A legislação estadual e municipal criada a partir de 1990}

Em meados de 1995, dispunham de leis aprovadas de incentivo fiscal à cultura o Distrito Federal (Brasília), quatro Estados (Pará, Pernambuco, Rio de Janeiro e São Paulo), oito capitais estaduais

\begin{tabular}{|} 
Conhecida como "lei \\
Sarnev", a primeira lei de \\
incentivo teve vida \\
relativamente curta e \\
seus resultados \\
quantitativos ainda näo \\
foram divulgados \\
oficialmente nem \\
avaliados com vigor.
\end{tabular}
(Aracaju, Belo Horizonte, Curitiba, Rio de Janeiro, Salvador, São Paulo, Teresina e Vitória) e três outros Municípios: Londrina, São Bernardo do Campo e Uberlândia. Este rol não inclui Municípios ou Estados que apenas tinham fundos de amparo às artes, como é o caso de Porto Alegre, Santo André e São José dos Campos, além do Estado do Espírito Santo. ${ }^{11}$ Há finalmente locais em que consta haver - mas não foi possível confirmar leis ou projetos de lei de incentivo fiscal à cultura: Municípios de Araraquara, Botucatu, Limeira, Piracicaba e Estados do Ceará, Piauí, Santa Catarina e Rio Grande do Sul.

As leis de âmbito estadual e municipal começaram a surgir no início desta década. Enquanto as primeiras reservam um percentual do ICMS (Imposto sobre Circulação de Mercadorias e Serviços), as segundas valem-se de tributos como o IPTU (Imposto sobre a Propriedade Territorial Urbana) e o ISS (Imposto Sobre Serviços). A legislação municipal tomou a dianteira temporal em relação à estadual, se bem que em ambos os níveis o mais freqüente são os casos de implantação lenta. Há defasagens por vezes longas entre a apresentação de projeto de lei ao legislativo, sua aprovação, sua regulamentação, a montagem de comissões de avaliação e a publicação dos primeiros editais.
11. Levantamento feito pelo Centro de Estudos da Cultura e do Consumo, EAESP/FGV, entre janeiro e maio de 1995 , junto a secretarias municipais e estaduais de cultura.

\section{Traços das leis de incentivo}

Um primeiro traço geral das leis de incentivo é a intenção de que elas estimulem as empresas a mobilizar uma parcela de seus recursos próprios no apoio a projetos culturais e assim possam abater um percentual de algum imposto a pagar. A participação dos recursos próprios varia entre 20 e $30 \%$ do custo de cada projeto, o que significa dizer que uma empresa só pode custear até $80 \%$ de um projeto com recursos que terão isenção fiscal. Entende-se que, se a lei não força a empresa a entrar com recursos próprios, é como se o governo sacrificasse uma massa de dinheiro público capaz de ser empregada diretamente por suas instituições culturais, para agir indiretamente, deixando às empresas a decisão do que financiar. Em outras palavras, seria como sacrificar receita pública convertendo-a em reforço do orçamento publicitário das empresas.

Um segundo traço é que todas as leis supõem o exame técnico de projetos como condição necessária para o financiamento. Em geral, o exame deve ser feito a partir de convocatórias públicas de projetos através de editais periódicos (trimestrais, quadrimestrais ou semestrais). As comissões que os analisam costumam contar com representantes do poder executivo (municipal ou estadual) das áreas de cultura e finanças e de um certo número de representantes de sindicatos ou outras associações de artistas ou produtores culturais. Com exceção das leis municipais de São Paulo e de Salvador, que admitem maioria para os representantes de entidades culturais (sete entre dez votos, em São Paulo, e cinco entre sete votos, em Salvador), nas demais se vê um equilíbrio entre os representantes do governo e das entidades artísticas. Como casos limites, as leis do Município de Londrina, no Estado do Paraná, e de Teresina, capital do Estado do Piauí, concentram poder em mãos de representantes das áreas de finanças, cultura e da chefia do executivo municipal. São indicados pela prefeitura sete dos doze membros previstos pela lei de Teresina e todos os membros da comissão já atuante em Londrina. O primeiro caso é caricatural: é o próprio prefeito, em pessoa, quem nomeia cinco membros, o mesmo número que as entidades culturais. Ou os prefeitos de Teresina costumam ser mais envolvidos e versados em cultura que os do resto do país, ou a sociedade civil local está em nível tão baixo de organização que não existem entida- 
des organizadas na área cultural, ou é clientelismo explícito mesmo.

Em nível estadual, a lei do Rio de Janeiro também prevê maioria de três para um entre os representantes do governo e das entidades culturais (ou seja, doze do governo e quatro das entidades culturais).

Um terceiro traço é que todas as leis vedam relações de proximidade social (parentesco e/ou participação em negócios comuns) entre membros das comissões de avaliação e autores de projetos. Como durante o período em que permanece como membro de uma dessas comissões, assim como no ano seguinte ao seu desligamento, ninguém pode recorrer a elas, a participação nessas comissões significa muitas vezes um considerável sacrifício econômico pessoal de algum artista ou produtor cultural. A apreciação de projetos e seu acompanhamento são cansativos e não-remunerados. Somando-se o tempo de trabalho em casa com o dispendido em reuniões, um membro da comissão consome dois dias inteiros por semana durante o mês que segue a cada um dos três editais abertos a cada ano e um dia inteiro por semana no resto do ano. É o tempo que cada membro tem para ler e analisar o conteúdo e o orçamento de 30 a 40 projetos ou para examinar suas prestações de contas. ${ }^{12}$ As leis procuram também evitar ligações de interesse entre financiados e financiadores. A este respeito, a lei federal é uma exceção, pois aceita que os grandes grupos econômicos possam manter instituição cultural permanente e aplicar, através dela, os seus recursos de isenção fiscal. São os casos dos institutos ou fundações filiados, por exemplo, a bancos e grupos financeiros. Em nível municipal, a lei de São Paulo também é exceção, posto que não proíbe vinculação entre produtor cultural e contribuinte.

Uma quarta característica do sistema é vedar às comissões a rejeição de projetos culturais a partir de uma avaliação de mérito. Assombrados com a lembrança nefasta da censura vigente durante o regime militar (196485 ), os autores dos projetos fizeram questão de deixar explícita essa interdição. Assim, devem as comissões limitar-se a examinar apenas a clareza e a precisão de cada projeto, o realismo dos orçamentos e prazos de execução, e demais condições previstas em lei. Resta saber como se comporta, na prática, tão enfática demonstração de neutralidade contida nas leis.

Um quinto traço é que a aprovação do projeto não é garantia de seu financiamento, como ocorre no sistema de fundos de fomento cultural ou científico. Nestes, quando o projeto é aprovado ele já está garantido, pois os recursos estão disponíveis. No caso dos incentivos fiscais à cultura, geralmente a aprovação do projeto apenas credencia, por um certo período de tempo, o seu autor (ou alguém em seu nome) a procurar uma empresa que o patrocine, embora possa haver casos em que o autor já nomeie uma empresa como interessada. Ou seja, a aprovação tem um período de validade de-

Embora sejam poucas as
informaçöes a respeito de
quem financia projetos
culturais, uma conclusaao
já se apresenta segura: a
de que vem crescendo
bastante o número de
empresas que aderem as
leis de incentivo fiscal à
cultura.
terminado. É claro que, se existe o risco de os produtores culturais não encontrarem patrocinadores para seus projetos, será razoável que as comissões tenham o direito de aprovar projetos em um valor superior ao disponível, o que tende a acontecer, como já ocorre na lei do Município de São Paulo. Mas as leis tendem a restringir essa possibilidade, uma vez que trabalham geralmente dentro de parâmetros fixos:

a) o percentual da massa de um mesmo imposto que os contribuintes podem sacrificar para o apoio à cultura (20\% na grande maioria dos casos, podendo chegar até $50 \%$ no caso da lei estadual paulista);

b) o percentual das estimativas de arrecadação do respectivo imposto, que varia entre $2 \mathrm{e} 5 \%$;

c) nenhum projeto, individualmente considerado, pode representar mais do que determinado percentual dos recursos colocados à disposição dos agentes culturais, para evitar que um ou alguns "megaprojetos" açambarquem a totalidade ou a maior parte dos recursos.

Um sexto traço é que, infelizmente, não se encara com bons olhos a remuneração de especialistas em formatar, produzir, administrar e captar recursos para projetos culturais. (Há leis que aceitam essa remuneração, limitando-a a um percentual máximo sobre o valor do projeto). Tenta-se assim evitar a formação de um segmento de especialistas em produção cultural, como se isso introduzisse alguma distorção irremediável. Outro cuidado que se vê em alguns
12. Esses cálculos foram feitos por pessoa experiente na administração da lei municipal de São Paulo. Seria de se perguntar o desastre que aconteceria se essa restrição de apresentar projetos fosse utilizada pelas agências de fomento à ciência, cuja clientela tem nas bolsas de pesquisa um complemento precioso de seus parcos vencimentos de professores universitários. 
textos legais é evitar que eventos "mundanos" (como coquetéis de vernissage ou noites de autógrafo) consumam parcela importante dos recursos previstos para um projeto cultural.

Um sétimo traço diz respeito à possibilidade ou não de o próprio governo que cria o incentivo poder se beneficiar dele. Ou seja, de as próprias agências de conservação ou fomento pertencentes ao governo incentivador poderem apresentar projetos às comissões. As leis em geral aceitam essa possibilidade de concorrência, ressalvando que qualquer projeto de governo tem de competir "em pé de igualdade" com os projetos apresentados por particulares. Percebe-se aí o grande perigo que o sucesso dessas leis introduz: o de os governos quererem transferir para os incentivos suas despesas correntes com seus eventos e com a manutenção de suas entidades culturais.

Um oitavo traço é que a definição dos segmentos culturais e atividades financiáveis através das leis varia de uma localidade a outra. Ou seja, como a cultura artística, além de múltipla em termos de linguagem, é suscetível de ter seu sistema de classificação flutuante ao longo do tempo, as definições de gêneros e atividades cobertas varia de uma a outra. Eventos e proteção ao patrimônio estão previstas em todas. A pesquisa em artes já não é freqüente $e$, infelizmente, apenas uma lei inclui apoio sob a forma de bolsas de estudo.

Uma nona e última característica é o âmbito sociogeográfico de cobertura das leis. A exigência de que os candidatos a verbas residam no Município ou Estado há um mínimo de anos, prioridades no financiamento de iniciativas que focalizem a cultura local ou ainda a exigência de que a iniciativa se realize ou seja divulgada em primeira mão no Município ou Estado que criou a lei são os requisitos mais comumente estabelecidos.

\section{RESULTADOS ALCANÇADOS E PERSPECTIVAS}

Embora a maioria das leis aqui comentadas não tenha produzido resultados reais em intensidade que permitam uma avaliação, outras há que já permitem alguma inferência.

$\mathrm{Na}$ cidade de São Paulo, a Lei Marcos Mendonça em seu primeiro ano de funcionamento, 1991, recebeu 253 projetos, dos quais aprovou vinte e viabilizou doze. Conseguiu repassar para os produtores culturais cerca de 272 mil dólares, o que significa uma "taxa de aproveitamento" de $3,4 \%$, posto que o total disponível era de oito milhões de dólares. Três anos depois, em 1994, tanto em número de projetos quanto em valor efetivamente gasto, seus resultados mostravam um considerável crescimento: 453 projetos apresentados, dos quais 236 aprovados e 44 realizados. Estes consumiram 6,5 milhões de dólares ou aproximadamente $33 \%$ dos 19,5 milhões de dólares disponíveis.

Embora sejam poucas as informações a respeito de quem financia, uma conclusão já se apresenta segura: a de que vem crescendo bastante o número de empresas que aderem as leis de incentivo fiscal à cultura. Em lugar de só se verem os poucos e tradicionais financiadores - grandes bancos privados ou públicos, empresas de petróleo, tabaco e bebidas, empreiteiras - pode-se ver um rol ampliado de setores, incluindo empresas de ônibus ou de limpeza pública, estacionamentos, papelarias, gráficas e editoras, fábricas de instrumentos musicais, escolas particulares e hotéis. Enfim, ramos de atividade em que se pode facilmente localizar grandes contribuintes de impostos municipais como ISS ou IPTU. É claro que a nova leva de patrocinadores mobiliza orçamentos pequenos (um ou alguns milhares ou dezenas de milhares de reais), enquanto um grande patrocinador tem um orçamento anual - só para fomento à cultura - em torno de cinco a seis milhões de reais.

No que diz respeito à operacionalidade do sistema, talvez seja necessário aguardar ainda a entrada em vigor de um número maior de leis para se poder chegar a um balanço mais fiel. A propósito, das leis estaduais, apenas a do Rio de Janeiro entrou em vigor, mas sem resultados quantitativos ainda disponíveis.

Mas, como conciliar, na seleção de projetos, interesses de produtores culturais com as variantes de gosto e preferência dos vários segmentos sociais em matéria de cultura? Como evitar fraudes fiscais sem sacrificar a agilidade necessária ao sistema? Como simplificar a mecânica das leis para aumentar o círculo dos financiadores e dos financiados? Como integrar a participação das várias áreas governamentais afetadas pela legislação de incentivo, visando seu melhor funcionamento?

Há ainda um grande número de questões a serem equacionadas e resolvidas nesse percurso. Os agentes culturais da etapa que se inicia não poderão mais torcer o nariz à empresa privada, encarando a participação delas em cultura como profanação de um território sagrado. 